\title{
Ruptured Velamentous Vessel
}

National Cancer Institute

\section{Source}

National Cancer Institute. Ruptured Velamentous Vessel. NCI Thesaurus. Code C117350.

A fetal blood vessel in the placental membranes that appears torn upon gross inspection of the placenta. 